\title{
The in Vivo Use of Dithiothreitol in Cystinosis
}

\author{
DENISE DEPAPE-BRIGGER, HY GOLDMAN, AND CHARLES R. SCRIVER ${ }^{(30)}$ \\ The deBelle Laboratory for Biochemical Genetics, Medical Research Council Group in Genetics, McGill University-
} Montreal Children's Hospital Research Institute, Montreal, Quebec, Canada

EDGARD DELVIN

The Genetics Unit, Shriners Hospital, Montreal, Quebec, Canada

ORVAL MAMER

The Mass Spectrometry Unit, Royal Victoria Hospital, Montreal, Quebec, Canada

\begin{abstract}
Summary
Two male patients with late stage (uremic) infantile nephropathic cystinosis (INC) (Table 1) were treated by mouth with the reducing agent dithiothreitol (DTT), at doses not exceeding 25 $\mathbf{m g} \cdot \mathbf{k g}^{-1}$ body weight three times per day. Three sequential periods of observation were obtained in both patients: on thiol (8.5 months); off thiol (8-9 months); on thiol again (7 months or longer). Other than nausea and vomiting at the maximum dose range, no apparent toxicity was observed. One subject died in uremia in the 24th month of the study.

The half-cystine concentration in peripheral blood leukocytes decreased during both treatment periods in each patient from initial pretreatment levels in excess of $8 \mathrm{nmol} \cdot \mathrm{mg}^{-1}$ protein (normal $<0.1 \mathrm{nmol} \cdot \mathrm{mg}^{-1}$ ) to $10-20 \%$ of initial values (Table 2 and Fig. 1, $A$ and $B$ ). Reduction in total number of blood leukocytes or in the neutrophil fraction, where cystine storage occurs selectively in cystinosis, did not occur (Table 3) as a possible explanation for these findings; nor did storage of samples, a possible artifact, influence the cystine content of cystinotic cells (Fig. 2).

Multiple site rectal mucosa biopsy clearly revealed cystine storage but serial biopsies did not reflect a positive DTT response when compared with the leukocyte assay (Table 4). High intersample variation in cystine content, even between samples taken at one time, prevented measurement of a treatment response.
\end{abstract}

DTT had no apparent detrimental effect on the concentration of representative proteins, including hemoglobin (Table 3), serum insulin, and serum immunoglobulin during the treatment trials. Renal function (glomerular and tubular) was severely depressed and did not improve during the period of observation in either patient (Table 2; Fig. 3, $A$ and $B$ ).

Postmortem tissues from one patient revealed 10-40-fold excess cystine accumulation in kidney cortex and liver (Table 5). However, these levels of accumulation are at the lower range of or even below published values for cystine in cystinotic kidney and liver.

Whereas chemical methods are not reliable for detecting and measuring DTT in biologic fluids, preliminary evidence indicates that a silylated derivative of oxidized DTT can be detected in the urine of patients receiving DTT by mouth (Fig. 4). This finding suggests that the thiol is absorbed and excreted.

\section{Speculation}

The defect in cystine metabolism (or transport) in cystinosis remains unknown. However, if administered early in the course of INC, DTT might prevent the occurrence of irreversible phenotypic components by preventing cystine accumulation.

Infantile nephropathic cystinosis is a fatal autosomal recessive inborn error of cyst(c)ine metabolism $(20,23)$. Adolescent nephropathic cystinosis $(1,8,15)$ and adult benign cystinosis $(15$, $18,23)$ are considered to be variants, perhaps allelic, of the infantile type, in which a more benign clinical course appears to correlate with less extensive intracellular, presumably lysosomal, storage of cystine. Dietary methods of treatment do not offset the unknown intracellular defect of cyst(e)ine metabolism and, accordingly, do not alter the clinical course of INC (2). On the other hand, we have shown $(1,7,8)$ that the sugar thiol, threo2,3-dihydroxy-1,4-dithiolbutane (dithiothreitol or DTT), penetrates the living cell and will correct the abnormal cystine storage in cultured cystinotic fibroblasts in vitro. Earlier indications that DTT could be administered to human subjects (7) led us to examine the effect of long term administration of DTT in two patients with INC. Our results indicate that DTT, or equivalent thiols, might offer some hope in the treatment of this inborn error of cystine storage.

\section{MATERIALS AND METHODS}

\section{PATIENTS}

Two 8-year-old boys ( $S L$ and $P F)$, both in the late stages of INC, were enrolled in June 1973 in a trial of DTT treatment, under conditions of informed parental consent. Typical findings concerning growth failure, cystine storage, and renal failure were evident in both patients (Table 1). $S L$ died of renal failure at $97 / 12$ years during the later stages of this investigation. $P F$ is still alive at 11 years (in April 1976). Previous observations on their fibroblasts and leukocytes are compatible with the INC phenotype (half-cystine content exceeded $8 \mathrm{nmol} \cdot \mathrm{mg}^{-1}$ protein in both patients). Patient $P F$ has experienced $3 \mathrm{~cm}$ of linear growth between the 20th and 32 nd month of the study, coinciding with the second DTT trial; there was no change in height during the first 20 months. No increase in height occurred in the other subject.

\section{PROTOCOL}

The investigation consisted of two periods of DTT treatment separated by an interval without DTT. The first treatment period began in June 1973 and ended in February 1974; the second trial began in October 1974. Results on tissue cystine content 
are reported up to the time of death (April 1975) for $S L$ and up to November 1975 for patient PF. The concentration of creatinine and urea nitrogen in serum, and of cystine in leukocytes was measured monthly in both patients. The average of several determinations was used to determine the "baseline" values for the CUSUM plots (see below). Rectal biopsy every 2 months was used in the first treatment period, but was found to be inadequate for quantitative monitoring of the DTT response. Slit lamp examination of the cornea was also performed at intervals.

Table 1. Clinical data for patients with in fantile nephropathic cystinosis before dithiothreitol (DTT) trial

\begin{tabular}{|c|c|c|}
\hline & Patient SL & Patient PF \\
\hline Age (yr) & $79 / 12$ & $82 / 12$ \\
\hline Weight age (at 50th percentile) & $36 / 12$ & $64 / 12$ \\
\hline Height age (at 50 th percentile) & $34 / 12$ & $46 / 12$ \\
\hline Serum creatinine $\left(\mathrm{mg} \cdot \mathrm{dl}{ }^{\prime}\right)$ & $2.6^{\prime}$ & $1.6^{1}$ \\
\hline $\begin{array}{l}\text { Endogenous creatinine clearance } \\
\left(\mathrm{ml} \cdot \min ^{-1} / 1.73 \mathrm{~m}^{2}\right)\end{array}$ & $15-18^{1}$ & $23-24^{1}$ \\
\hline $\begin{array}{l}\text { Leukocyte half-cystine concentration }{ }^{2} \\
\text { (nmol-mg ' protein) }\end{array}$ & $13-38^{1}$ & $8-17^{1}$ \\
\hline \multicolumn{3}{|c|}{$\begin{array}{l}\text { 'Mean (or range) of at least three determinations. } \\
2 \text { Data pooled from observations in previous } 36 \text { months; "control" } \\
\text { samples obtained immediately before first treatment trial with DTT were } \\
\text { lost in laboratory accident. }\end{array}$} \\
\hline
\end{tabular}

\section{DTT DOSAGE AND ROUTE OF ADMINISTRATION}

The initial dosage schedule for DTT was approximately 7 $\mathrm{mg} \cdot \mathrm{kg}^{-1}$ every $8 \mathrm{hr}$ by mouth; the dose was gradually increased until it reached approximately $25 \mathrm{mg} \cdot \mathrm{kg}^{-1}$ every $8 \mathrm{hr}$ (or 12 capsules/day). The odor of the capsules and nausea and vomiting associated with DTT usage at the upper dose levels affected compliance with the treatment regimen and the scheduled ingestion of DTT was not maintained consistently.

Enteric-coated capsules of DTT powder $(250 \mathrm{mg})$ were prepared by ICN or Horners Pharmaceutical Co. (Montreal). DTT was purchased from ICN (Canada).

\section{PREPARATION OF SAMPLES}

Leukocytes were separated from whole blood by drawing 10 $\mathrm{ml}$ venous blood into a syringe containing a mixture of dextran $(2 \mathrm{ml})$ and heparin $(1 \mathrm{ml})(5)$. After standing upright for $45 \mathrm{~min}$ at $37^{\circ}$ the supernatant fluid containing leukocytes was discharged into a tube. The remaining erythrocytes were then removed by differential hypotonic lysis; leukocytes were recovered as a button after centrifugation and stored at $-20^{\circ}$ unless sonicated immediately. The leukocytes were suspended in $2.0 \mathrm{ml}$ water and sonicated at $22 \mathrm{kc} \cdot \mathrm{sec}^{-1}$ (4 pulses of $15 \mathrm{sec}$ each) using an M. S. ultrasonic disintegrator and deproteinized immediately with $2.0 \mathrm{ml}$ sulfosalycilic acid $(3 \% \mathrm{w} / \mathrm{v})$. The cystine-containing supernatant was separated by centrifugation at $27,000 \times g$ for $20 \mathrm{~min}$, and stored at $-20^{\circ}$ until analysis.

Table 2. Leukocyte half-cystine and serum creatinine values in cystinosis patients receiving dithiothreitol (DTT)

\begin{tabular}{|c|c|c|c|c|c|}
\hline \multirow[b]{2}{*}{ Regimen } & \multirow{2}{*}{$\begin{array}{l}\text { Elapsed time in } \\
\text { study (mo) }\end{array}$} & \multicolumn{2}{|c|}{$\begin{array}{l}\text { Leukocyte half-cystine } \\
\text { (nmol } \cdot \mathrm{mg}^{-1} \text { protein) }\end{array}$} & \multicolumn{2}{|c|}{ Serum creatinine $\left(\mathrm{mg} \cdot \mathrm{dl}^{-1}\right)$} \\
\hline & & $S L$ & $P F$ & $S L$ & $P F$ \\
\hline Pretreatment & 0 & $13-38$ & $8-17$ & $<3.0$ & $<2.0$ \\
\hline \multirow[t]{9}{*}{ On DTT at zero mo } & 1 & & 6.6 & 2.0 & 2.0 \\
\hline & 2 & 37.5 & & 3.1 & 1.9 \\
\hline & 3 & 18.2 & 4.9 & 2.2 & 2.0 \\
\hline & 3.5 & & & 2.5 & 1.6 \\
\hline & 4 & 13.3 & & 1.9 & 2.0 \\
\hline & 5 & 9.0 & & 3.2 & 1.8 \\
\hline & 6 & 3.8 & 2.7 & 2.4 & 2.0 \\
\hline & 7 & 4.8 & 1.3 & 2.5 & 1.9 \\
\hline & 8 & 1.3 & 4.9 & 2.5 & 1.9 \\
\hline \multirow[t]{9}{*}{ Off DTT at $8.5 \mathrm{mo}$} & 9 & & 2.3 & & 2.4 \\
\hline & 10 & 6.2 & 2.2 & 3.2 & 1.9 \\
\hline & 11 & 2.5 & & 3.4 & 2.6 \\
\hline & 12 & 4.7 & 3.7 & 3.4 & 1.9 \\
\hline & 12.5 & 5.4 & & 3.8 & \\
\hline & 13 & 2.4 & 8.0 & 4.6 & 2.2 \\
\hline & 14 & 3.1 & 1.7 & & 2.6 \\
\hline & 15 & 9.7 & 8.4 & 4.4 & 2.1 \\
\hline & 16 & 5.5 & 3.2 & 4.4 & 2.5 \\
\hline \multirow[t]{14}{*}{ On DTT again at $17 \mathrm{mo}(S L)$ and $18 \mathrm{mo}(P F)$} & 17 & 9.0 & 5.8 & 5.3 & 2.9 \\
\hline & 18 & & 6.4 & 4.6 & 2.7 \\
\hline & 19 & 6.8 & & 4.9 & \\
\hline & 20 & 7.4 & 6.2 & 5.0 & 3.0 \\
\hline & 21 & 2.6 & 4.6 & 5.9 & 2.8 \\
\hline & 22 & 3.6 & 4.0 & 5.3 & 3.2 \\
\hline & 23 & & 1.3 & 6.2 & 3.3 \\
\hline & 24 & (Died) & 4.2 & (Died) & 3.6 \\
\hline & 25 & & 3.6 & & 3.4 \\
\hline & 26 & & 3.1 & & 3.3 \\
\hline & 27 & & 6.0 & & 3.3 \\
\hline & 28 & & 5.9 & & 3.6 \\
\hline & 29 & & 3.9 & & 3.1 \\
\hline & 30 & & 5.7 & & 3.2 \\
\hline
\end{tabular}


Biopsy of rectal mucosa was performed with a Rubin tube at 2-month intervals in the initial phases of the study. Multiple samples of rectal mucosa (3-7 $\mathrm{mg}$ each) were obtained, from different sites which were individually homogenized and then deproteinized as described for leukocytes.

Samples of tissues obtained at autopsy from $S L$ were stored intact at $-20^{\circ}$ until they were homogenized in distilled water, and then deproteinized as described above.

\section{ANALYSIS OF SAMPLES}

Protein was analyzed by the method of Lowry et al. (13). Halfcystine was analyzed by elution chromatography on ion exchange resin columns by the method of Spackman. Stein, and Moore (24) on a modified Beckman-Spinco amino acid analyzer fitted with an expanded range recorder $(4.5-5.0 \mathrm{ml})(22)$. The reproducibility of half-cystine analysis on our analyzer is $\pm 3.5 \%$ by this method. Creatinine (3) and urea nitrogen (14) were measured by standard automated methods on a Technicon analyzer.

\section{GAS CHROMATOGRAPHY OF DITHIOTHREITOL}

Aliquots of urine (about $50 \mathrm{ml}$ ), obtained from patient $P F$ during periods when DTT was either administered by mouth or withheld. were evaporated almost to dryness in a Buchler flash cvaporator. Ethanol $(99 \%, 10 \mathrm{ml})$ was added to the concentrated urine, allowed to chill at $4^{\circ}$, and spun at $4,500 \times g$ for 10 $\mathrm{min}$ in a refrigerated centrifuge (Sorvall $\mathrm{RC} 2-\mathrm{B}$ ). The supernatant was removed and the ethanol evaporated off under a nitrogen stream overnight. DTT powder ( $>99 \%$ in the thiol form) was dissolved in ethanol and partially oxidized in air to the disulfide. A mixture of DTT and urine was also prepared.

A large excess of N,O-bis-(trimethylsilyl)-acetamide (BSA) was added to the samples $(0.1 \mathrm{ml}$ to a few crystals of DTT powder; $1.0 \mathrm{ml}$ to the urine precipitate), since we were unable to prepare a completely anhydrous urine precipitate. The sample containing BSA was then heated at $60^{\circ}$ for $5 \mathrm{~min}$. An aliquot (3 $\mu$ l) was injected into an LKB 9000 gas chromatograph-mass spectrometer. The conditions for analysis were: stationary phase, a glass column ( 6 by $1 / 4$ inch) containing OV 101 on Chromosorb $W$; gas phase, helium, flow rate $35 \mathrm{ml} \cdot \mathrm{min}^{-1}$; column temperature programmed from $90^{\circ}-280^{\circ}$ with an increase of $5^{\circ} / \mathrm{min}$; injector temperature, $280^{\circ}$; separator temperature, $280^{\circ}$; ion source temperature, $270^{\circ}$; ionization energy, 70 $\mathrm{eV}$.

\section{PRESENTATION OF DATA}

The sequential leukocyte half-cystine values are presented in tabular form and also by the method of cumulative sum analysis (CUSUM) (9). This method makes possible assessment of trends in the treatment response from serial data collected at intervals. CUSUM plots dilute background analytic "noise" and indicate significant changes which might not be detectable initially in a plot with random variation from the mean. In the present long term study we found this technique of considerable use to monitor the response to DTT. Consistent trends which are not initially evident from tabulations of primary data can be revealed clearly by CUSUM analysis (9). In order to use CUSUM analysis, however, it is necessary to determine a relevant baseline. In the absence of any information about the "normal" range for a particular measurement it is necessary to select a baseline re-
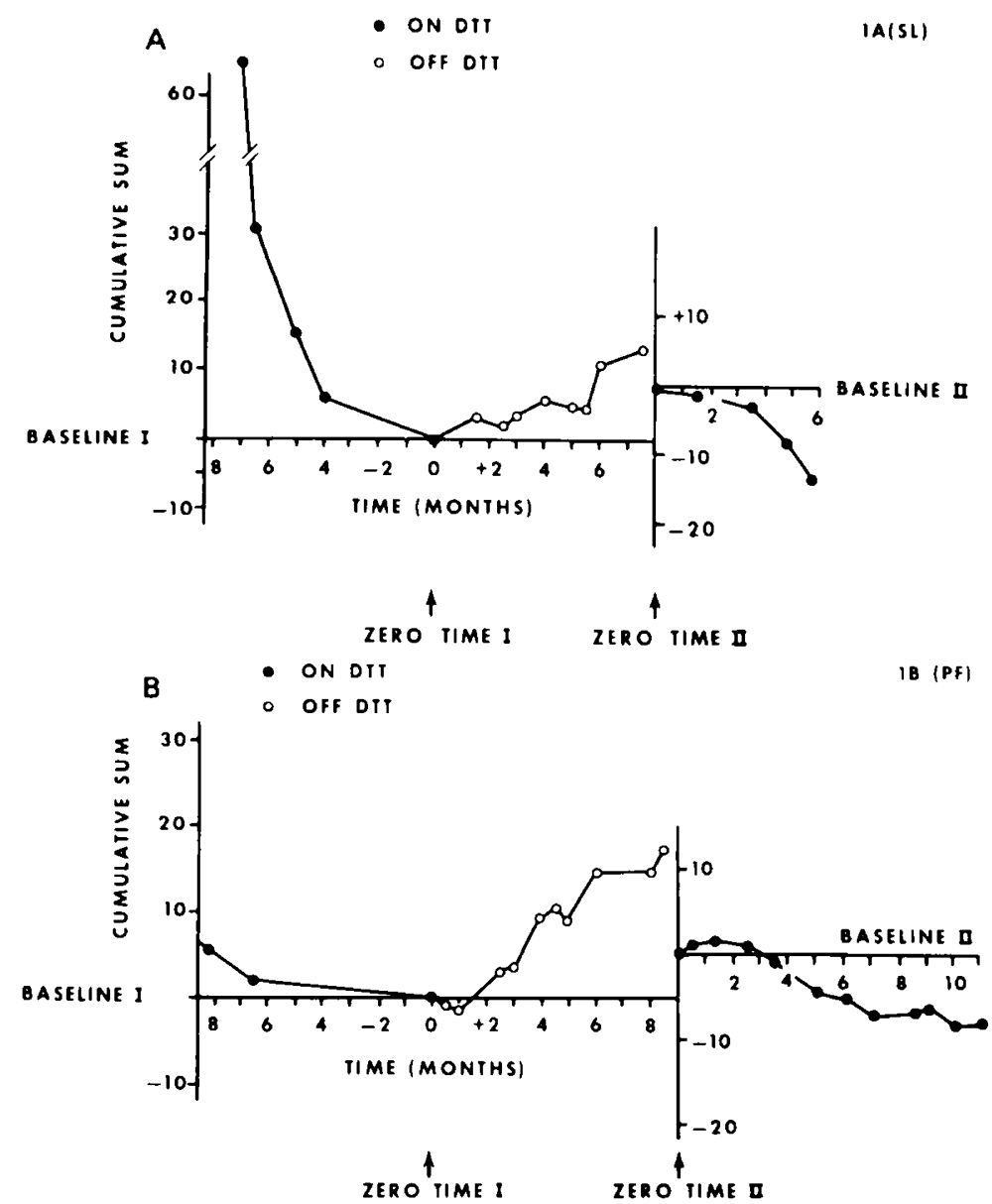

Fig. 1. CUSUM plots for change in leukocyte half-cystine content during treatment $(\bullet)$ with dithiothreitol and during the period of withdrawal $(O)$ in patient $S L(A)$ and in patient $P F(B)$. 
Table 3. Leukocyte cystine content related to total leukocyte concentration and neutrophil fraction in cystinosis patients receiving dithiothreitol (DTT)

\begin{tabular}{|c|c|c|c|c|c|c|c|c|c|c|c|}
\hline \multirow[b]{3}{*}{ Regimen } & \multirow[b]{3}{*}{$\begin{array}{l}\text { Elapsed } \\
\text { time in } \\
\text { study } \\
(\text { mo) }\end{array}$} & \multicolumn{5}{|c|}{ Patient SL } & \multicolumn{5}{|c|}{ Patient PF } \\
\hline & & \multirow[b]{2}{*}{$\begin{array}{l}\text { Leukocytc } \\
\text { 1/2-cystinc, } \\
\text { nmol-mg } \\
\text { protein }\end{array}$} & \multicolumn{2}{|c|}{ Leukocytes } & \multirow[b]{2}{*}{$\begin{array}{l}\text { Retic., } \\
\%\end{array}$} & \multirow[b]{2}{*}{$\begin{array}{l}\mathrm{Hb}, \\
\mathrm{g} \cdot \mathrm{dl} \quad \mathrm{I}\end{array}$} & \multirow[b]{2}{*}{$\begin{array}{l}\text { Leukocyte } \\
1 / 2 \text {-cystine, } \\
\text { nmol·mg ' } \\
\text { protein }\end{array}$} & \multicolumn{2}{|c|}{ Leukocytes } & \multirow[b]{2}{*}{$\begin{array}{c}\text { Retic., } \\
\%\end{array}$} & \multirow[b]{2}{*}{$\begin{array}{l}\mathrm{Hb}, \\
\mathrm{g} \cdot \mathrm{dl}^{-1}\end{array}$} \\
\hline & & & $\begin{array}{l}\text { Total, } \\
\text { per } \\
\operatorname{mm}^{3} \times \\
10^{3}\end{array}$ & $\begin{array}{l}\text { Neu- } \\
\text { tro.. \% }\end{array}$ & & & & $\begin{array}{c}\text { Total, } \\
\text { per } \\
\mathrm{mm}^{3} \times \\
1()^{3}\end{array}$ & $\begin{array}{l}\text { Neu- } \\
\text { tro.. \% }\end{array}$ & & \\
\hline Pretreatment & 0 & $13-38$ & 6.4 & 56 & 0.3 & 10.7 & $8-17$ & 6.8 & 44 & 0.5 & 13.3 \\
\hline \multirow[t]{4}{*}{ On DTT } & 4 & 1.3 .3 & 10.6 & 49 & & 10.3 & & & & & \\
\hline & 6 & 3.8 & 5.9 & 53 & 2.0 & 10.3 & 2.7 & 8.2 & 56 & 1.8 & 12.3 \\
\hline & 7 & 4.8 & 5.7 & 57 & 3.0 & 13.3 & 1.3 & 5.6 & 74 & 2.4 & 12.3 \\
\hline & 8 & 1.3 & 9.0 & 62 & 2.8 & 11.0 & 4.9 & 6.5 & 69 & 1.6 & 13.0 \\
\hline \multirow[t]{2}{*}{ Off DTT (at $8.5 \mathrm{mo}$ ) } & 10 & 6.2 & 7.9 & 53 & 1.8 & 10.3 & & & & & \\
\hline & 14 & & & & & & 1.7 & 7.1 & 62 & 2.0 & 10.3 \\
\hline \multirow{6}{*}{$\begin{array}{l}\text { On DTT at } 17 \mathrm{mo}(S L) \text { and } 18 \\
\operatorname{mo}(P F)\end{array}$} & 17 & 9.0 & 8.4 & 73 & & 8.2 & 5.8 & & & & \\
\hline & 20 & & & & & & 6.2 & 3.4 & 58 & 1.8 & 10.0 \\
\hline & 21 & 2.6 & 5.7 & 66 & 1.8 & 5.6 & 4.6 & 4.5 & 48 & 1.0 & 9.9 \\
\hline & 22 & 3.6 & 5.0 & 67 & 1.2 & 5.4 & 4.0 & & & & \\
\hline & 23 & & & & & & 1.3 & 4.8 & 64 & 1.6 & 10.6 \\
\hline & 24 & $\leftarrow$ & Died-_ & - & 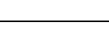 & $\longrightarrow$ & 4.2 & 6.2 & 6() & 1.4 & 10.6 \\
\hline
\end{tabular}

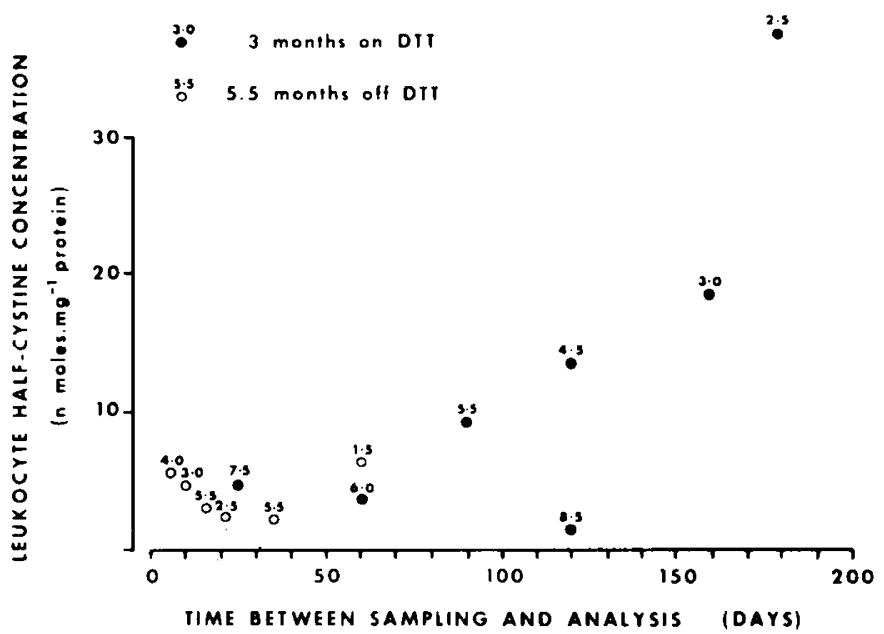

Fig. 2. The relation between leukocyte half-cystine concentration (ordinate), elapsed time that intact cell pellet was kept in storage at $-20^{\circ}$ before sonication and deproteinization for analysis of cystine (abscissa). and duration (in months) of dithioreitol (DTT) treatment (number beside symbols). The change in leukocyte half-cystine is related to the duration of DTT therapy while the duration of cell pellet storage is not a determinant.

flecting the quasisteady state. The baseline for leukocyte halfcystine concentration in the first phase of the investigation was chosen by averaging three values at the end of the first cycle of treatment; successive deviations (positive or negative) from this baseline were summed and plotted according to the CUSUM method. (A pretreatment baseline was not available because a laboratory accident caused the loss of samples collected just before the first treatment period.) A second baseline was chosen at the end of the period of DTT withdrawal and before the second treatment period, to evaluate the effect of the second treatment regimen. The three last values in the withdrawal period were averaged for this baseline, and subsequent deviations from it were summed cumulatively and plotted.
Table 4. Half-cystine content of rectal mucosa of cystinosis patients receiving dithiothreitol $(D T T)$ (nanomoles $\cdot \mathrm{mg}^{-1}$ protein)

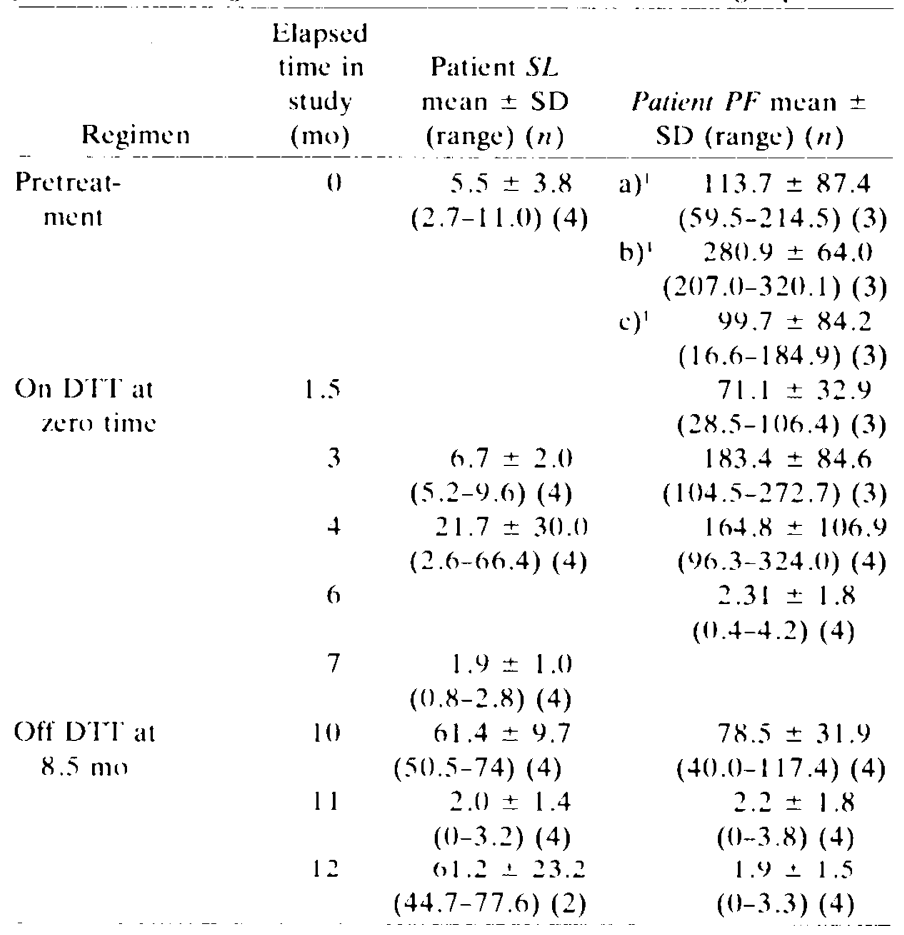

1 Three separate studies during a 12 -month period before DTT treatment.

\section{RESULTS}

CLINICAL STATUS

No overt signs of toxicity to DTT were observed other than nausea and vomiting at the uppermost dosage. Melena was absent. Serum insulin levels were not depressed by DTT and immunoglobin levels remained normal. Neutropenia, protein- 
uria, and skin lesions have been reported following D-penicillamine therapy (11); such complications did not occur in our study.

\section{TISSUE (YSTINE IN VIVO)}

The half-cystine concentration of circulating leukocytes exceeded $8 \mathrm{nmol} \cdot \mathrm{mg}^{-1}$ protein (normal value, $<0.1 \mathrm{nmol} \cdot \mathrm{mg}^{-1}$ protein) (15), in both patients before treatment with DTV (Table 1). Leukocyte cystine fell during DTT treatment in both patients, then increased during the phase of DTT withdrawal and diminished again during the second period of DTT treatment (Table 2; Fig. 1, $A$ and $B$ ). Cystine accumulation does not occur in circulating lymphocytes in cystinosis (21). We performed differential cell counts in the course of our study to determine whether the apparent decline in leukocyte cystine during D'T treatment was caused by a relative decline in the neutrophil fraction. The differential and total leukocyte counts did not alter significantly throughout the period of observation (Table 3).

Another factor known to modify cellular cystine content is storage of cells. Kroll and colleagues (12) observed that the halfcystine content of cystinotic fibroblasts fell by half in the initial few days of storage of cell pellets at $-20^{\circ}$ or $-70^{\circ}$. During the first DTT trial in our study, leukocytes were stored as pellets for periods up to 180 days before analysis. In the present study, the concentration of half-cystine is clearly influenced more by the duration of DTT treatment than by the duration of cell storage before cystine analysis (Fig. 2). Nonetheless, in order to guard against even slight perturbation of cystine determination by storage, deproteinized supernatants were prepared immediately from fresh leukocyte sonicates and analyzed on the same day in the second DTT trial. Leukocyte half-cystine fell again during the second DTT trial (Table 2 and Fig. $1 . A$ and $B$ ), indicating that this observation is not an artifact of sample handling.

Rectal mucosa can be used for the diagnosis of cystinosis (10). However, even with biopsies from multiple mucosal sites, we did not find the technique useful to monitor the response to DTT in the first trial. Intersample variation in eystine content was very great even among samples taken from a patient on the same day; and alse from one time to the next (Table 4). Accordingly, we did not pursue these observations in the second trial of DTT treatment.

Slit lamp examination of cystine content in cornea was also evaluated in our patients as a monitor of treatment response. Photographs taken under standardized conditions to estimate the density of erystals revealed no apparent change in the course of the present study.

\section{RENAL FUNCTION}

Renal function was monitored by serum creatinine concentration, endogenous creatinine clearance, and various indicators of tubular function in cystinosis, as described previously (8). Creatinine clearance rates $\left(\mathrm{ml} \cdot \mathrm{min} 1 / 1.73 \mathrm{~m}^{2}\right)$ fell from $16-18$ before DTT treatment to 7-10 at the time of death in $S L$; and from 2324 before DTT treatment to 16-17 at the present time in $P F$. Serum creatinine rose in both patients during the same periods
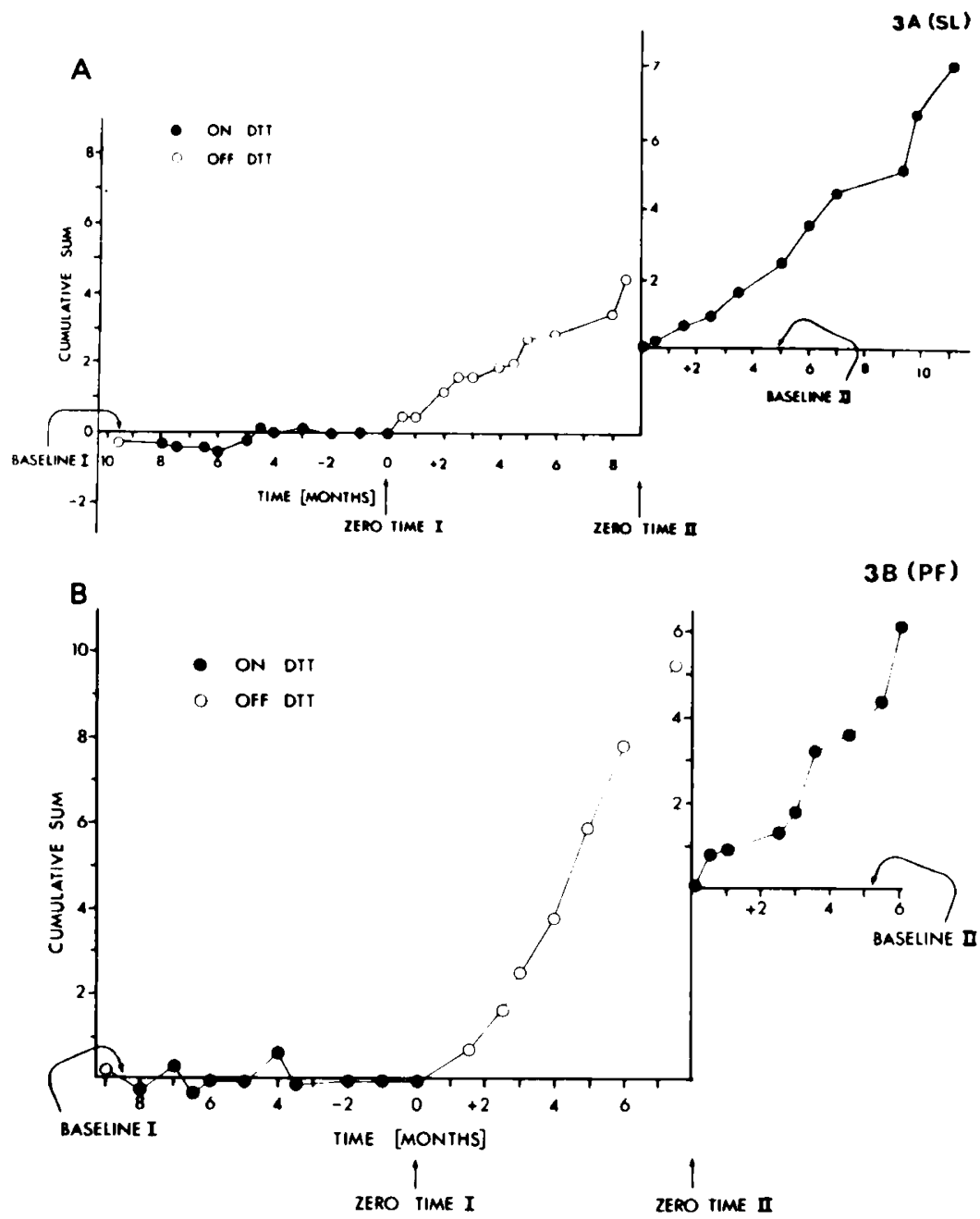

Fig. 3. CUSUM plots for change in serum creatinine during treatment $(\bullet)$ with dithiothreitol and during the period of withdrawal $(O)$ in patient $S L(A)$, and in patient $P F(B)$. 
Table 5. Half-cystine concentration of postmortem tissues

\begin{tabular}{|c|c|c|c|c|c|c|}
\hline \multirow[b]{2}{*}{ Tissue } & \multicolumn{2}{|c|}{ Patient $\mathrm{SL}^{1}$} & \multicolumn{2}{|c|}{ Other cystinotics } & \multicolumn{2}{|c|}{ Normal } \\
\hline & $\begin{array}{c}\mathrm{nmol} \cdot \mathrm{mg}^{-1} \text { wet } \\
\mathrm{wt}\end{array}$ & $\begin{array}{c}\mathrm{nmol} \cdot \mathrm{mg}^{-1} \\
\text { protein }\end{array}$ & $\begin{array}{c}\mathrm{nmol} \cdot \mathrm{mg} \\
\text { wt }\end{array}$ & $\begin{array}{c}\mathrm{nmol} \cdot \mathrm{mg}^{-1} \\
\text { protein }\end{array}$ & $\begin{array}{c}\mathrm{nmol} \cdot \mathrm{mg}^{-1} \text { wet } \\
\mathrm{wt}\end{array}$ & $\begin{array}{c}\mathrm{nmol} \cdot \mathrm{mg} \\
\text { protein }\end{array}$ \\
\hline \multicolumn{7}{|l|}{ Brain } \\
\hline Gray matter & $0.138,0.197$ & & $0.036,0.076^{2}$ & & $0.193^{2}$ & \\
\hline White matter & $0.050,0.093$ & & $0.020,0.055^{2}$ & & $0.151^{2}$ & \\
\hline Kidney cortex & $19.8,21.0$ & $72.5,116$ & $\begin{array}{l}18.5-181^{3} \\
(n=11)\end{array}$ & $\begin{array}{c}24.6-1812^{4} \\
(n=14)\end{array}$ & $<0.25^{2}$ & $1.8,2.8^{2}$ \\
\hline Liver & 34.5 .42 .4 & & $\begin{array}{l}46-805 \\
(n=2)\end{array}$ & & & \\
\hline
\end{tabular}

' Died April 1975 at $97 / 12$ years during second treatment period; data are for two separate samples of each tissue.

2 From Schulman (19, 20).

${ }^{3}$ Pooled data cited in Schulman (19.20) and Schneider (16).

4 From Schncider (16) and Schulman (19, 20).

s Cusworth (4).

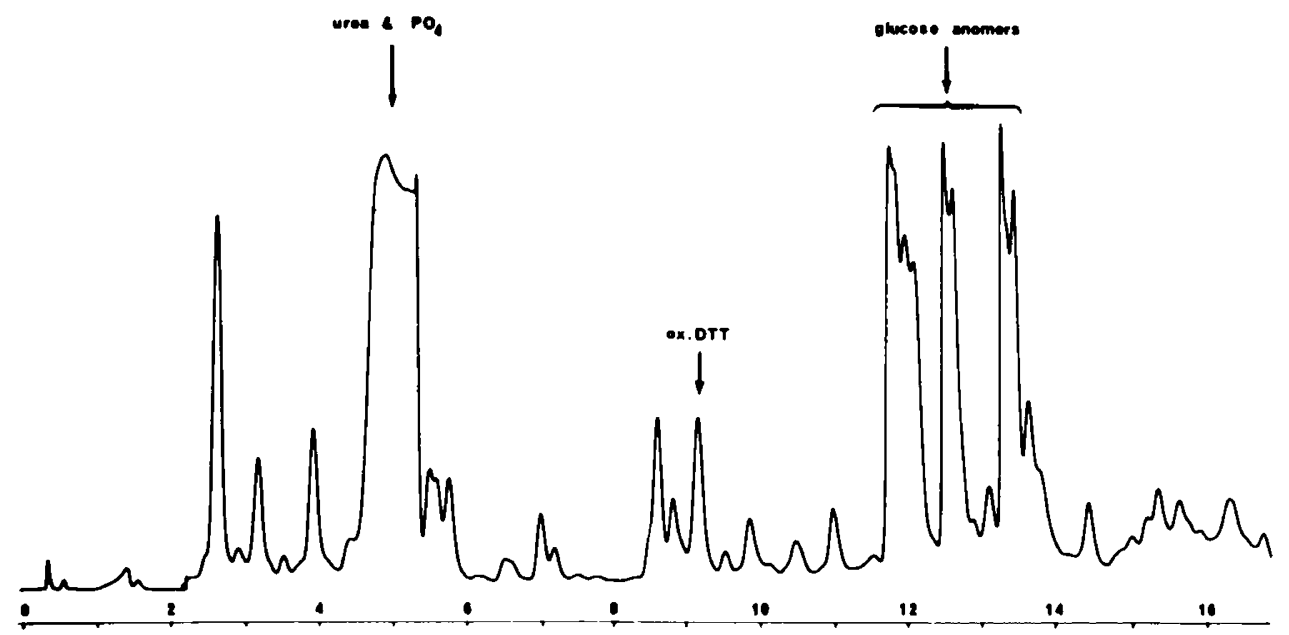

Fig. 4. Urine from patient $P F$ while receiving DTT by mouth showing gas chromatographic peaks for oxidized DTT, urea, phosphate, and other metabolites. The peak with 9 min retention time labeled as oxidized dithiothreitol $(o x . D T T)$ coelutes with authentic standard and yields an appropriate mass spectrum. The retention time for reduced DTT coincides with that for the glucose anomers. Mass spectrometry revealed no reduced DTT in this sample. Conditions for the analysis are described under Materials and Methods. The chart speed for the scan was $12.5 \mathrm{~mm} \cdot \mathrm{min}{ }^{\prime}$.

of observation. However, in both patients, there was some apparent attenuation in the progress of renal failure during the first DTT trial as reflected in serum creatinine values (Table 2; Fig. 3, $A$ and $B$ ). This finding was not evident in the second trial. There was no change in the abnormal urinary composition associated with cystinosis.

\section{POSTMORTEM TISSUE CYSTINE}

The half-cystine content of frozen, postmortem tissues was examined in patient $S L$ (Table 5). Solid tissues were stored at $-20^{\circ}$ until their cystine content was measured; storage under these conditions does not appear to affect the determination of cystine. The half-cystine content of brain was not elevated, a finding which has been reported previously in cystinosis (19, 20). The half-cystine content of kidney was greatly elevated; however, the observed values (Table 5) were distributed at the lower end of the range for postmortem values in ICN kidney ( 19 , 20). Half-cystine content of liver from our patient who had been treated with DTT was lower than in other samples of cystinotic liver known to us (Table 5).

\section{MEASUREMENT OF DTT IN BODY FLUIDS}

We were unable to measure DTT accurately in urine as a yellow chromophore at $412 \mathrm{~nm}(25)$ when it is reacted with Ellman's reagent $\left(5,5^{\prime}\right.$-dithiobis|2-nitrobenzoic acid], DTNB) after reduction with sodium borohydride (6). Poor sensitivity of the assay and poor recovery of DTT in urine were responsible. Gas chromatography (GC) proved to be a more promising method of analysis.

The GC scan of the solution containing a mixture of oxidized and reduced DTT showed two main peaks. The one for oxidized DTT eluted early $(9 \mathrm{~min})$ at $190^{\circ}$ while the reduced form eluted later $(13.5 \mathrm{~min})$ at $220^{\circ}$.

The urine sample from patient $P F$ obtained when he was receiving DTT, revealed many peaks on the GC scan (Fig. 4). However, a peak with a retention time of 9 min coincided with the bis-trimethylsilylated derivative of cyclic (oxidized) DTT; oxidized DTT standard and urine peak coeluted. Any reduced DTT that might have been present in urine was masked by glucose and other monosaccharides; however, reduced DTT was not observed in this region even when the mass spectra of eluted urine material were compared with the mass spectrum of a standard. DTT (oxidized or reduced) was not detected in urine when the patient was not receiving the substance.

The mass spectrum of cyclic DTT (disulfide) standard is also identical to the substance presumed to be DTT (disulfide) in the urine sample. The molecular ion of DTT is evident at $\mathrm{m} / \mathrm{e}$ (mass/ charge) 296 with intensity of $23.7 \%$ related to the most intense base peak at $\mathrm{m} / \mathrm{e} 116$.

These findings indicate that DTT can be detected as disulfide in urine by gas chromatography. Urine contains DTT, which is in the oxidized form, when the patient is receiving DTT by mouth. 


\section{DISCUSSION}

The present study provides initial evidence that the abnormally elevated endogenous cystine content in INC can be diminished in vivo by orally administered DTT. The thiol promotes a decrease in cystine concentration in peripheral leukocytes (neutrophils). During the first treatment period, leukocyte half-cystine concentration decreased in both of our patients; it then increased when DTT was withdrawn, and again diminished in the second treatment period. The decrease in leukocyte halfcystine was not accounted for by a preferential decline in the neutrophil fraction of peripheral blood leukocytes during exposure to DTT.

Leukocytes were stored at $-20^{\circ}$, as intact cell pellets, up to 180) days during the first treatment period. Although the halfcystine content of intact INC fibroblasts diminishes during storage (12), our data indicate that storage of intact leukocytes was not the cause of their diminished half-cystine content in the present study. Accordingly, we believe this change was probably an effect of DTT administration which has been shown in vitro to deplete the cystine excess of cystinotic tissues $(1,7,8)$.

Although rectal mucosa biopsy and slit lamp examination of the cornea are both useful techniques for the diagnosis of cystinosis, neither method permitted us to observe a response to DTT when compared with the leukocyte response. Irregular cystine deposition in rectal mucosa and wide intersample variation may explain the erratic quantitative results derived from the samples of rectal mucosa. However, the failure to observe a response in nonleukocyte tissues may indicate that DTT did not reach and act upon their cystine stores in contrast to its apparent ability to do so in circulating leukocytes.

DTT will penetrate the plasma membrane of cells in vitro (1) and, at $0.1 \mathrm{mM}$ in vitro, it is taken up by tissues without adverse effect on tissue respiration or upon membrane transport functions. Present evidence suggests that DTT and other thiols are probably maintained in the SH form by the intact cell (16). Accordingly, it was of interest to know whether DTT actually entered the body from the intestinal lumen in the present trial. Our GC method indicates that oxidized DTT is excreted in the urine when it has been administered by mouth, implying that DTT is released from the enteric-coated capsules and absorbed from the intestine in which case it may be available for uptake by leukocytes and perhaps also by solid tissues.

DTT was tolerated in vivo by our patients at the dosage schedule used in the present study. No alterations in the plasma levels of proteins containing disulfide bonds $(e . g$. , insulin and immunoglobulins) were observed in the present (6) and in our earlier study $(1,7)$. The lathyritic-like effect which has been experienced by patients receiving D-penicillamine (11) was not observed in the present trial with DTT.

Other workers have observed an in vivo leukocyte-cystine response to exogenous thiol administration (16); in those studies cysteamine was used. A trial with the nonthiol reducing agent. ascorbic acid, is also under way but the in vivo response to this agent is unknown at the present time (16).

Our findings suggest that DTT offers little hope for alteration of the natural course of INC in patients when nephropathy (or other tissue damage) is advanced. The apparent plateau effect in the deterioration of renal function during the first DTT trial in our patients (Fig. 3) was not repeated in the second trial; this first response may indeed be part of the natural process of the illness in its preterminal stages. In our case it was unlikely to be the result of any improved clinical management or intervention since the frequency of observation and of patient visits did not change from the pre-DTT treatment routine.

It is likely that primary prevention of cellular cystine accumulation in the young patient will be required if the secondary and irreversible phenotypic events are to be avoided. Our postmortem studies in patient $S L$, which reveal a rather low half-cystine content of kidney and liver by available standards for frozen postmortem samples of cystinotic tissue (References 4, 17, and 20), give us some hope that solid tissues, as well as leukocytes, may be able to respond to DTT, despite our negative finding obtained in this respect regarding rectal mucosa and the uveal tract. However, to determine whether the fatal course of INC can be diverted or arrested, it will be necessary to devise a more palatable form of medication, or an alternate route of DTT administration, so that further studies in younger patients can be pursued.

\section{CONCLUSION}

If clinical prognosis in the various forms of cystinosis (infantile nephropathic, adolescent nephropathic, and adult benign) is in any way related to the degree of abnormal intracellular accumulation of cystine, then depletion of the excess cystine stores in the nephropathic forms of cystinosis may ameliorate the disease process. We have studied the effect of the reducing thiol, dithiothreitol, given by mouth at doses not exceeding $25 \mathrm{mg} / \mathrm{kg}$ body weight, three times daily, in two patients with infantile nephropathic cystinosis. The half-cystine content of peripheral blood leukocytes was slowly decreased by DTT treatment; it then reaccumulated when DTT was not given; leukocyte kinetics did not otherwise seem to be perturbed by DTT. Rectal mucosa biopsies and corneal slit lamp examinations, albeit helpful for diagnosis, did not reveal a solid tissue response to thiol. Renal function did not improve during thiol treatment. No serious untoward effects were observed during 31 patient-treatment months with DTT. Silylation of oxidized DTT permitted its detection in urine of patients receiving the chemical by mouth, indicating absorption and excretion of the thiol.

\section{REFERENCES AND NOTES}

1. Aaron, K., Goldman, H., and Scriver, C. R.: Cystinosis; new observations: 1 Adolescent (type III) form. 2. Correction of phenotypes in vitro with dithiothreitol. In: N. A. J. Carson and D. N. Raine: Inherited Disorders of Sulphur Metabolism, pp. 150-161 (Churchill-Livingstone, Edinburgh, 1971).

2. Bickel, H. Lutz, P., and Schmidt, H.: The treatment of cystinosis with diet or drugs. In: J. D. Schulman: Cystinosis, pp. 199-223, (No. (NIH) 72-249, United States Department of Health. Education and Welfare. Public Health Service, National Institutes of Health, Washington, D.C., 1972).

3. Chasson, A. L.. Grady, H. T., and Stanley, M. A.: Determination of creatinine by means of automatic chemical analysis. Amer. J. Clin. Pathol., 35:83 (1961)

4. Cusworth, D. C.: Personal communication, 1975.

5. Delvin, E. E., Scriver, ( . R., Pottier, A.. Clow, C. L., and Goldman, H.: Maladie de Tay-Sachs: Dépistage et diagnostic prénatal. Union Méd. Can.. 101: 683 (1972)

6. DePape-Brigger, D.: Unpublished thesis data (1975).

7. Goldman, H., Scriver, C. R., Aaron. K.. and Pinsky, L.: Use of dithiothreitol to correct cystine storage in cultured cystinotic fibroblasts. Lancet, $i: 811$ (1970).

8. Goldman, H., Scriver, C. R., Aaron, K., Delvin. E., and Canlas, Z.: Adolescent cystinosis: Comparisons with infantile and adult forms. Pediatrics, 47: 979 (1971).

9. Healy, M. J. R.: The disciplining of medical data. Brit. Med. Bull., 24: 210 (1968).

10. Holtzapple, P. G. Genel, M.. Yakovac, W. C., Hummeler, K., and Segal, S.: Diagnosis of cystinosis by rectal biopsy. N. Engl. J. Med., 281: 143 (1968).

11. Katz, R.: Penicillamine-induced skin lesions, a possible example of human lathyrism. Arch. Dermatol.. 95: 196 (1967).

12. Kroll, W. A., Becker, F. L. A., and Schncider, J. A.: Measurement of intracellular amino acids in cultured skin fibroblasts. Biochem. Med., 10: $368(1974)$.

13. Lowry. O. H.. Rosebrough, N. J., Farr, A. C., and Randall, R. J.: Protein measurement with the Folin phenol reagent. J. Biol. Chem., 193: 265 (1951).

14. Marsh. W. H.. Fingerhut, B., and Miller, H.: Automated and manual direct methods for the determination of blood urea. Clin. Chem., 11:624 (1965).

15. Schneider. J. A.: Clinical aspects of cystinosis. In: J. D. Schulman: Cystinosis, pp. 11-22, (No. (NIH) 72-249, United States Department of Health, Education and Welfare, Public Health Service, National Institutes of Health, Washington, D.C.. 1972).

16. Schneider, J. A.: Personal communication (1975).

17. Schneider, J. A.: Recent advances in cystinosis. In: W. L. Nyhan: Heritable Disorders of Amino Acid Metabolism, pp. 618-637 (John Wiley and Sons. New York, 1974).

18. Schneider, J. A.. Wong. V., Bradley, K.. and Seegmiller, J. E.: Biochemical comparisons of the adult and childhood forms of cystinosis. N. Engl J. Med., 279: 1253 (1968).

19. Schulman, J. D.: Cystine storage disease: Investigations at the cellular and subcellular levels. In: N. A. J. Carson and D. N. Raine: Inherited Disorders 
of Sulphur Metabolism, pp. 123-140 (Churchill-Livingstone, Edinburgh, 1971).

20. Schulman, J. D. (ed.): Cystinosis (No. (NIH) 72-249, United States Department of Health. Education, and Welfare, Public Health Service, National Institutes of Health. Washington, D.C., 1972).

21. Schulman, J. D., Wong, V. G.. Kuwubara, T., Bradley, K. H., and Seegmiller, J. E.: Intracellular cystine content of leukocyte populations in cystinosis. Arch. Intern. Med., 125: 660 (1970).

22. Scriver, C. R., Davies, E., and Lamm, P.: Accelerated selective short column chromatography of neutral and acidic amino acids on a Beckman-Spinco Analyzer. modified for simultaneous analysis of two samples. Clin. Biochem. $I: 179$ (1968).

23. Seegmiller, J. E., Friedman, T., Harrison, H. E., Wong, V.. and Schneider, J. A.: Cystinosis: Combined clinical staff conference at the National Institutes of Health. Ann. Intern. Med., 68: 883 (1968).

24. Spackman. D. H. Stein, W. H., and Moore, S.: Automatic recording apparatus for use in the chromatography of amino acids. Anal. Chem., 30: 1190 (1958).

25. We are grateful to Professor H. Taylor, University of Otago, Dunedin, New Zealand, for suggesting the chemical method for DTT measurement. Details of these studies are available elsewhere (6).

26. Presented in part at the Annual Meeting of the Canadian Society for Clinical Investigations, Winnipeg, January 1975 (Goldman, H., DePape-Brigger, D., Delvin, E., and Scriver, C.: Clin. Res., 22: 740A (1974)).

27. Consent for this project was obtained under informed conditions and the protocol was reviewed by the Standing Committee on Ethics of the Montreal Children's Hospital.

28. This work was supported by grants from the Medical Research Council (Studentship to D. DePage-Brigger), the Quebec Network of Genetic Medicine, and the McGill University-Montreal Children's Hospital Research Institute.

29. The source material for this manuscript was submitted in partial fulfillment of the requirements for a Master's thesis in the Department of Biology, McGill University.

30. Requests for reprints should be addressed to: C. R Scriver M.D. The DeBelle Laboratory for Biochemical Genetics, Medical Research Council Group in Genetics. McGill University-Montreal Children's Hospital, Research Institute, 2300 Tupper St., Montreal, Quebec H3H 1 P3 (Canada).

31. Received for publication May 11, 1976

32. Accepted for publication July 29, 1976.

\title{
The Biologic Activities of Cystic Fibrosis Serum. I. The Effects of Cystic Fibrosis Sera and Calcium Ionophore A 23187 on Rabbit Tracheal Explants
}

\author{
BRUCE IAN BOGART \\ Department of Cell Biology', New York University Medical Center, New York, New' York, USA
}

ELAINE J. CONOD, AND JAMES H. CONOVER(25)

Department of Pediatrics, Albert Einstein College of Medicine, Bronx, New York, USA

\begin{abstract}
Summary
An ionophore A23187-induced increase in membrane permeability to calcium ions in culture medium produced a rabbit tracheal mucociliary response indistinguishable from that caused by cystic fibrosis (CF) sera on three different occasions. Specific chelation of calcium ions with EGTA in the basal medium Eagle (BME) media with no additive or in native CF sera abolished the mucociliary disturbances in all cases. Increased membrane permeability to calcium may be important in the production of the mucociliary response by $\mathrm{CF}$ serum factor(s) in the tracheal assay system.
\end{abstract}

\section{Speculation}

CF serum factor(s) may be acting on the cultured rabbit tracheal explant cellular membranes to produce altered permeability to ions. This alteration in membrane permeability may be promoting a loss of intracellular communication and cellular injury. Such changes on the celluiar level may be related to the pathophysiology of this genetic disorder.

Cystic fibrosis is an autosomal recessive disease that is characterized by the dysfunction of many exocrine glands $(6,11)$. Although elevated sodium chloride in the sweat of CF subjects remains the most reliable parameter of the disease (5), the existence of a serum factor(s) in affected and carrier subjects, capable of producing in vitro mucociliary disturbances $(4,19)$, seems relevant to some aspects of the pathophysiology of the disease. Whole sera from CF and obligate heterozygous subjects have been described as promoting the so-called ciliary dyskinesia response when exposed to pieces of cultured rabbit tracheal ciliated epithelium $(4,19)$. In addition, sweat and saliva from CF-affected individuals promotes an alteration in the ionic content of salivary secretions upon retrograde perfusion (12-14).

The biologic mechanisms through which CF homozygote and heterozygote sera mediate the observed alterations in the tracheal epithelial bioassay system are not understood. However, the biologic basis in ciliary disturbances and secretory processes have been linked to elevated intracelluar calcium levels in several other experimental systems involving mollusks (17) and mammalian mast cells $(3,10)$. In these systems, an experimentally induced increase in membrane permeability to calcium ions by ionophore A 23187 resulted in functional alterations in ciliary movememt and secretory processes. Ionophore A23187 selectively increases membrane permeability to calcium ions (15.16. 21).

In an effort to determine whether inceased permeability to calcium ions could explain the CF serum response in the tracheal bioassay system, we selectively increased the membrane perme- 